\title{
About the Implementation of the Finite Element Method for Computer Aided Education in Electrical Engineering
}

\author{
F. Buret, O. Fabregue, D. Muller, A. Nicolas, L. Nicolas, F. Thollon \\ CEGELY - UPRESA 5005 \\ Ecole Centrale de Lyon \\ BP 163 - 69131 Ecully cedex - France
}

\begin{abstract}
We present in this paper how the 2D Finite Element Method may be optimized in order to get real time solving for Computer Aided Education applications. Three examples of such packages are described: the first one is used by students to understand the distribution of the magnetic field in a nonlinear magnetic circuit. The second one allows to understand the distribution of eddy currents in a conductive and magnetic sheet, and the third one is used to approach the flux density repartition in DC motors.
\end{abstract}

Index terms - Education, Finite elements method, Magnetic circuits, Eddy currents, DC motors.

\section{INTRODUCTION}

The traditional teaching of electrical engineering is facing the problem of using only abstract notions like charges, fields or induced currents in materials. Furthermore, these notions are manipulated using even more abstract vector or differential operators. This is one of the main reasons why most students in the domain of electricity do not have a deep understanding of the basic principles, even if they are able to solve standard problems.

We have now the possibility to use the fantastic power of the today's desktop computers to find new and more intuitive representations of the studied phenomena. This offers to the students easy-to-use and highly interactive software packages and lead them to understand intuitively and deeply the most basic laws and notions.

The main problem, when designing such an application, is to give an instant response to any modification of parameters: any user interaction has to cause a modification of the displayed results in a sufficiently short delay. Therefore, a judicious solving method has to be chosen depending on:

- The quantities that the teacher wants to show.

- The range of input parameters.

- The time needed to solve the problem.

The CEGELY is involved in the field of the Computer Aided Education (C.A.E.) for Electrical Engineering since a few years [1]. Table 1 shows how the solving method has been chosen depending on the nature of the application. In some cases, the choice of an analytical solving is obvious [2]. On the other hand, the finite element method (F.E.M.) is more adapted, especially when local quantities have to be represented in a whole space (such as the distribution of flux density or eddy current density), and when no simple analytical equation may be solved.

The object of this paper is to show how the F.E.M. may be optimized in order to get computation time compatible with a "real time" behavior. We present in a first part how this objective may be reached. In a second part, three applications for C.A.E. are described: Contact, for the understanding of the distribution of the flux density in non linear magnetic circuit, Coufou, for the understanding of the distribution of eddy currents in a conducting and/or magnetic sheet, and Motcc for an approach of the flux density repartition in DC motor.

\section{THE SPEED OPTIMIZATION OF THE F.E.M.}

The F.E.M. by itself is well known for $2 \mathrm{D}$ magnetostatics or eddy currents problems, and it does not lead to any particular difficulty [3]. Main work concerns actually the optimization of the implementation of the F.E.M. in order to minimize the solving times. This is the key point: on one hand, for C.A.E. considerations, great accuracy in the displayed results is not necessary; on the other hand, fast solving time is required to allow a real feedback.

To achieve this objective, following points are respected:

- The discretization is performed using first order triangles.

- The structure of the mesh does not vary, which means that the structure of the F.E. matrix does not vary: the matrix is consequently prestored.

- The mesh is structured. Only the vertical location of some nodes may vary: in the airgap (Contact), or in the skin depth (Coufou).

- All local sub-matrices are precomputed, except the submatrices corresponding to elements which can be modified: in the airgap (Contact), or in the skin depth (Coufou).

- The nested dissection renumbering algorithm [4] is used to solve the system matrix.

- In non linear cases (Contact or Motcc), the initial solution is taken from the previous state of the magnetic circuit, thus decreasing the number of needed iterations. 
TABLEI

WHICH METHOD FOR WHICH PROBLEM?

\begin{tabular}{|c|c|c|c|c|}
\hline Problem & dimension & objectives & chosen method & why? \\
\hline $\begin{array}{l}\text { flux density in airgap of } \\
\text { rotating machine: } m \text { Field }\end{array}$ & 1D & $\begin{array}{l}\text { How to obtain a rotating field? What } \\
\text { does it mean? }\end{array}$ & analytical & very fast \\
\hline guided micro-waves: mWave & $2 \mathrm{D}$ & $\begin{array}{l}\text { understand propagation modes in } \\
\text { rectangular/circular waveguides }\end{array}$ & analytical & very fast \\
\hline $\begin{array}{l}\text { flux density, energy in a } \\
\text { magnetic circuit with air-gap: } \\
\text { Contact }\end{array}$ & $2 \mathrm{D}$ & $\begin{array}{l}\text { understand leakage flux, saturation. } \\
\text { Where is the electromagnetic energy? }\end{array}$ & finite element method. & $\begin{array}{l}\text { local quantities and nonlinear } \\
\text { problem }\end{array}$ \\
\hline $\begin{array}{l}\text { flux density in a DC motor: } \\
\text { Motcc }\end{array}$ & $2 \mathrm{D}$ & $\begin{array}{l}\text { see Contact. What is the influence of } \\
\text { the compensation windings? }\end{array}$ & finite element method & $\begin{array}{l}\text { local quantities and nonlinear } \\
\text { problem }\end{array}$ \\
\hline $\begin{array}{l}\text { eddy-current in a single sheet: } \\
\text { Coufou }\end{array}$ & $2 \mathrm{D}$ & $\begin{array}{l}\text { understand eddy-currents distribution } \\
\text { for different types of material, for } \\
\text { different frequencies }\end{array}$ & finite element method. & local quantities \\
\hline $\begin{array}{l}\text { impedance of a coil above } \\
\text { coated sheet (thickness } \\
\text { measurement): Planlmp }\end{array}$ & $2 \mathrm{D}$ & $\begin{array}{l}\text { What is the evolution of the } \\
\text { impedance versus the materials } \\
\text { properties and the frequency? }\end{array}$ & analytical & $\begin{array}{l}\text { global quantity with a wide } \\
\text { range of variations of the } \\
\text { parameters. }\end{array}$ \\
\hline
\end{tabular}

\section{FIRST EXAMPLE: THE CONTACT PACKAGE}

The studied device is the magnetic circuit of a double- $U$ shaped contactor. The magnetic field is created by one or two DC coils. With this type of application, we expect the students to understand the magnetic phenomena, including the influence of the saturation, to get the range values of these phenomena, and to understand some physical concepts, such as Ampere's law.

Using the corresponding arrow buttons (Fig. 3), the students can modify geometrical parameter (the airgap), electrical parameters (the current and the number of turns of both coils), and magnetic parameters (the relative permeability at the origin of the $\mathrm{B}-\mathrm{H}$ curve, and the flux density at saturation for both arms of the contactor). As results, they visualize the amplitude of the flux density and the field lines. They have also access to a real time updated table of results, showing field values, flux through airgap, energies... (Fig. 3).

With Contact, a 2D nonlinear magnetostatics problem is solved:

$$
-\frac{\partial}{\partial x}\left(v \frac{\partial A}{\partial x}\right)-\frac{\partial}{\partial y}\left(v \frac{\partial A}{\partial y}\right)=J
$$

The nonlinear equation is linearized by using the chord method [2]. A relaxation factor is used to force the convergence. This method is generally seen as highly inefficient, because the convergence depends on how close the initial guess is to the actual solution.

However the variations of parameters are always smooth due to the interactivity with the user. Therefore the actual solution is never far away from the initial guess, and the number of iterations is then reduced.

Only half of the geometry is discretized because of the vertical symmetry. Four layers of mesh are used in the airgap, because it can vary from $0.1 \mathrm{~mm}$ to $45 \mathrm{~mm}$. The mesh is then made of 468 triangles and 270 nodes (Fig. 1). On a mid-range workstation with a 75 Mips computation power (HP9000/712), a linear solution takes about $30 \mathrm{~ms}$ to be computed, and a nonlinear solving goes up to $250 \mathrm{~ms}$ if 8 iterations are required to converge (Table II). Note that these $\mathrm{CPU}$ times are compatible with the maximum delay required by a smooth animation.

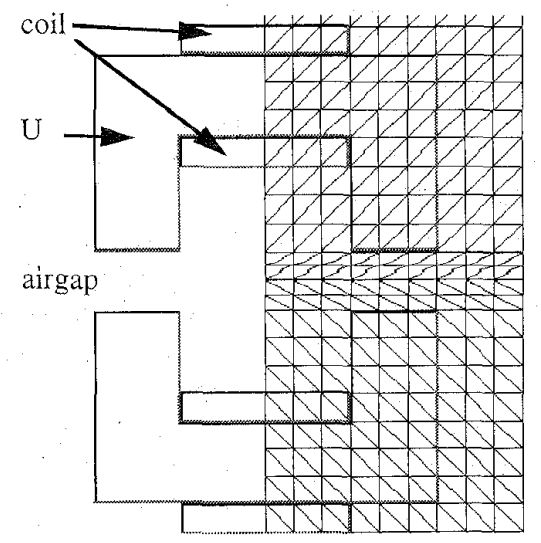

Fig. 1: Contact mesh. 
III. SECOND EXAMPLE: THE MotCC PACKAGE

The same basic idea as developed for Contact is used for Motcc. The studied device is the magnetic circuit of a DC motor with rotor, stator and compensation windings. The students can modify the current in each winding. They visualize the amplitude of the flux density (Fig. 4).

They can study :

- The armature reaction (in particular the flux density repartition in a pole and the saturation of a part of the pole).

- The action of the compensation winding for solving the previous problem.

The nonlinear magnetostatic equation is solved by using the chord method, and the initial guess of the iterative process is the solution of the previous magnetic state.

There is a symmetry along the horizontal axis. The mesh is made of 407 nodes and 720 triangles (Fig. 2), leading to a 50 $\mathrm{ms}$ linear solution and up to $1 \mathrm{~s}$ in the strong nonlinear cases (Table II).

\section{Third Example: The Coufou Package}

The objective of CouFou is to allow students to understand intuitively how the eddy currents are created and distributed in a single sheet excited with a cylindrical coil when varying parameters such as conductivity and permeability of the sheet, coil sizes or excitation frequency [5]. Thus, following points are tackled:

- How is flux modified with a magnetic / non magnetic material, or with a conductive / non conductive material (Fig. 5)?

- How does the frequency modify the distribution of the flux and the current density?

- How is the eddy current distribution modified with all the previous properties?

Here, all materials have linear properties. From Maxwell's equations, a complex problem is expressed in term of potential magnetic vector $\mathbf{A}$.

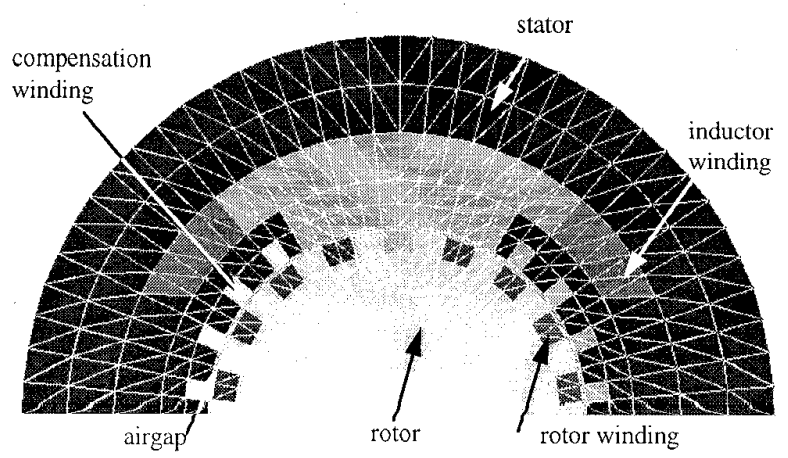

Fig. 2: Motcc mesh. $-\nabla\left(\frac{1}{\mu} \nabla \mathrm{A}\right)+\sigma \frac{\partial \mathrm{A}}{\partial \mathrm{t}}=\mathrm{J}_{\mathrm{ex}}$

where $\mu$ and $\sigma$ are the permeability and the conductivity of the sheet. $\mathrm{J}_{\mathrm{ex}}$ is the current density in the coil.

The implementation has been optimized as much as possible to reduce solving times:

The mesh structure does not vary except in the sheet where the size (but not the number) of the triangles is calculated in function of standard penetration depth $\delta$. For each new value of frequency, conductivity or permeability, a new discretization in the sheet is done in such a way that there are two triangles between the top of the sheet and a depth of $\delta$. The structure of the final finite element matrix is then prestored.

On a mid-range workstation with a 75 Mips computation power, the solving time is about $0.3 \mathrm{~s}$, which is also compatible with "real time" (Table II).

TABLE II

NUMBER OF NODES AND CPU TIME FOR THE FE APPLICATIONS SOLVING ON A HP9000/712 WORKSTATION

\begin{tabular}{lccc}
\hline Application & $\begin{array}{c}\text { number } \\
\text { of nodes }\end{array}$ & $\begin{array}{c}\text { CPU time } \\
\text { linear solution }\end{array}$ & $\begin{array}{c}\text { CPU time } \\
\text { nonlinear solution }\end{array}$ \\
\hline Contact & 270 & $30 \mathrm{~ms}$ & $250 \mathrm{~ms}$ \\
Motcc & 407 & $50 \mathrm{~ms}$ & $1000 \mathrm{~ms}$ \\
Coufou & 510 & $300 \mathrm{~ms}$ & \\
\hline
\end{tabular}

\section{CONCLUSION}

We have presented in this paper how the F.E.M. has been optimized in order to be used in Computer Aided Education packages: this optimization allows to solve a problem in a few milliseconds which is compatible with a smooth animation of the displayed solution. Three examples have been presented: Contact and Motcc, which are currently used at Ecole Centrale de Lyon in conjunction with an introdutory course to electrical engineering, and Coufou, which is used in a short course on non destructive testing.

\section{REFERENCES}

[1] D. Muller, L. Mariaux, A. Nicolas, "The Colos project - Applications in the domain of electrical engineering," REEE AP-S/URSI Int. Symp., Newport Beach (CA), June 18-24, 1995.

[2] D. Muller, L. Nicolas, A. Nicolas, "A C.AE. Package for an Intuitive Approach to Microwaves," IEEE Transactions on Magnetics, vol. 30, pp 3216-3219, Sept 1994

[3] S.R.H. Hoole, Computer Aided Analysis and Design of Electromagnetic Devices, Elsevier, New York, 1989

[4] A. Ceorge, J.W. Liu, Computer Solution of Large Sparse Positive Definite Systems, Prentice-Hall, Englewood Cliffs, NJ, 1981.

[5] F. Thollon, D. Muller, L. Nicolas," A C.A.E. Package for Understanding Eddy Currents Repartition," ElectrIMACS, St Nazaire, France, sept 17 18-191996. 
3442
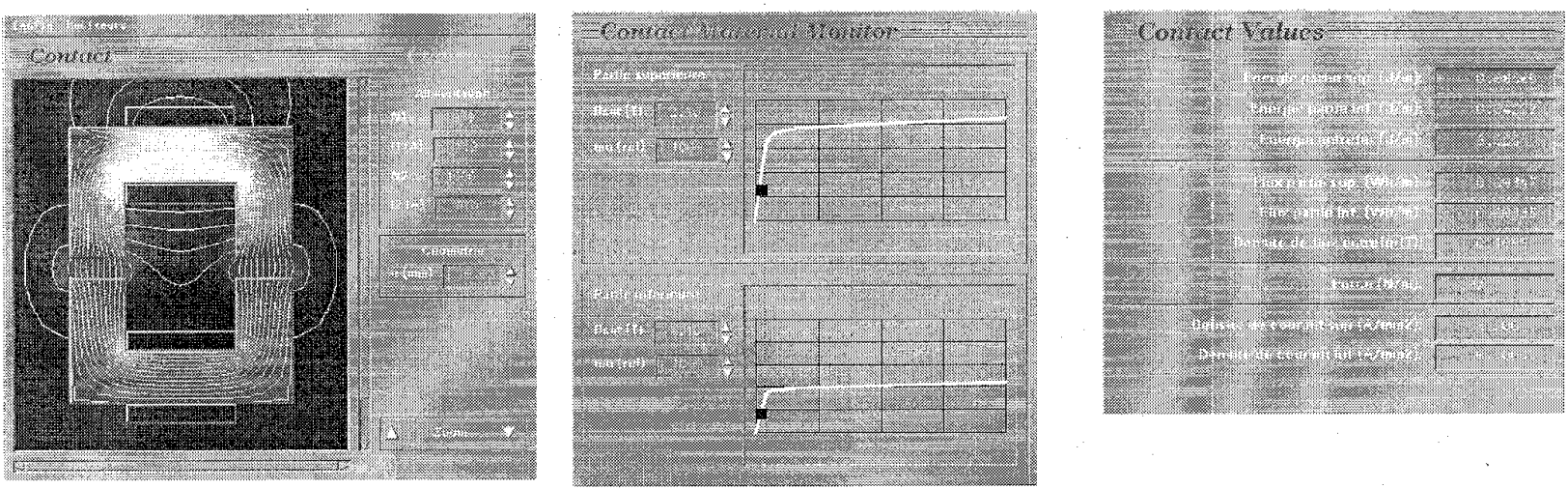

Fig. 3: Contact user interfaces: main window (left), material properties (middle), value window (right).
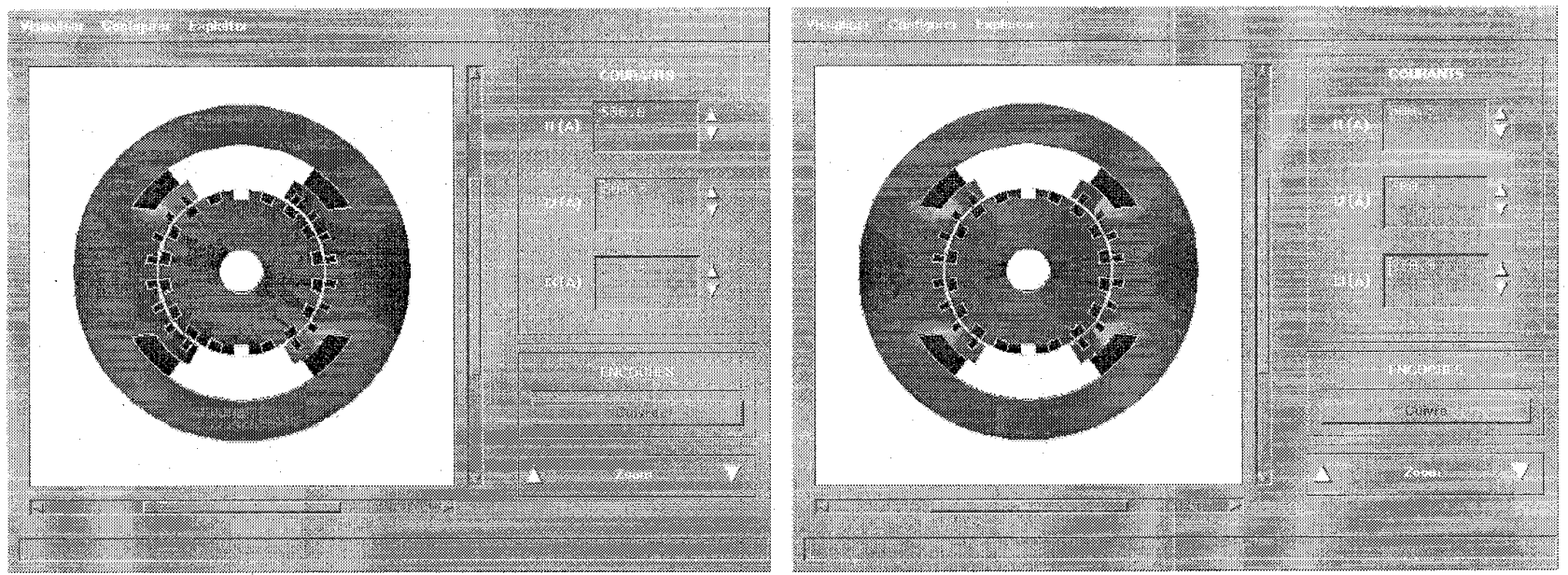

Fig. 4: Motcc user interfaces: armature reaction (left), action of compensation winding (right),
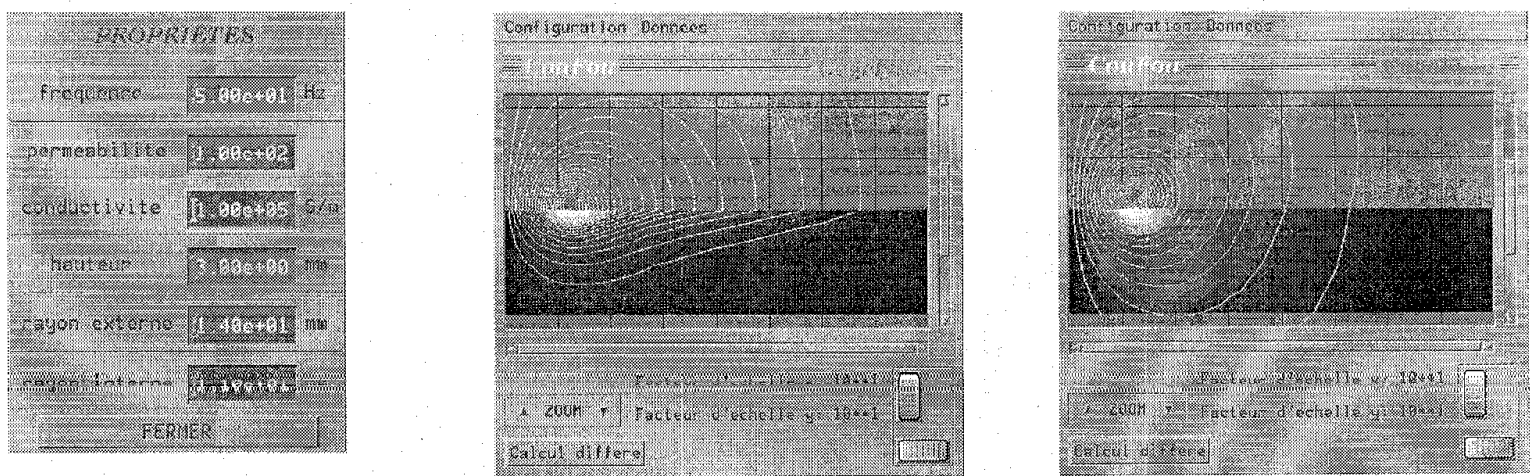

Fig. 5: Coufou user interfaces: data window (left), main window for magnetic material (middle) and nonmagnetic material (left). 